\title{
Aramid composites impregnated with different reinforcement: nanofibers, nanoparticles and nanotubes
}

\begin{abstract}
In this study, the electrospun nanofibers, nanoparticles and nanotubes were used as reinforcement in order to improve mechanical properties of materials for ballistic protection. The samples of polyurethane/p-aramid multiaxial fabric forms (Twaron fabrics and Colon fabrics) were impregnated with poly (vinyl butyral) (PVB) ethanol solution with the different content of reinforcement. Due to the improvement in mechanical, ballistic and impact properties, the surface modification of the fabrics with $y$-aminopropyltriethoxysilane (AMEO silane)/ethanol solution was used and silica nanoparticles were modified with AMEO silane. This study is divided into three parts of research: electrospinning process, ballistic testing of the $p$-aramid composites and impact tester analysis of the Colon composites. The mechanical properties of all the composites were tested by the dynamic mechanical analysis (DMA).
\end{abstract}

Keywords: p-aramid composites, Silica nanoparticles, Carbon nanotubes, AMEO silane, $\mathrm{PVB} / \mathrm{SiO}_{2}$ nanofibers, Ballistic testing, Impact testing.

\section{INTRODUCTION}

Electrospinning is a simple and unique technology for producing polymer fibers from polymer solutions and polymer melts. The produced fibers are in the micrometre and nanometre scale diameters [1]. The process of electrospinning is driven by a high voltage source to charge the polymer solution. These free charges are on the surface or inside a polymer liquid. The liquid is then accelerated toward a grounded metal collector of opposite polarity. The fiber jet travels allowing the solvent to evaporate from it, thus leading to the deposition of the solid polymer fibers on the collector. In fact, as the jet moves towards the collector, the electrostatic forces accelerate and stretch the jet. Stretching and evaporation of the solvent cause the jet diameter to become smaller. The basic electrospinning set-up consists of a syringe filled with the polymer solution, a needle, a high voltage source and a grounded conductive collector [2]. An electric field is initiated between the tip of a syringe and the collector and thus the electrostatic forces are generated. Under the influence of an electrostatic field, a pendant droplet of the polymer solution at the end of the syringe is deformed into the conical shape called Taylor cone. When these forces overcome the surface tension of the polymer solution, a jet is ejected from the tip of the syringe. Then, the solvent from the jet evaporates leading to the randomly oriented fibers on the collector [3-5].

Author'address: University of Belgrade, Faculty of Technology and Metallurgy, Karnegijeva 4, Belgrade, Serbia

Received for Publication: 01. 06. 2014.

Accepted for Publication: 12. 08. 2014.
The schematic drawing of the electrospinning process is illustrated in Figure 1.

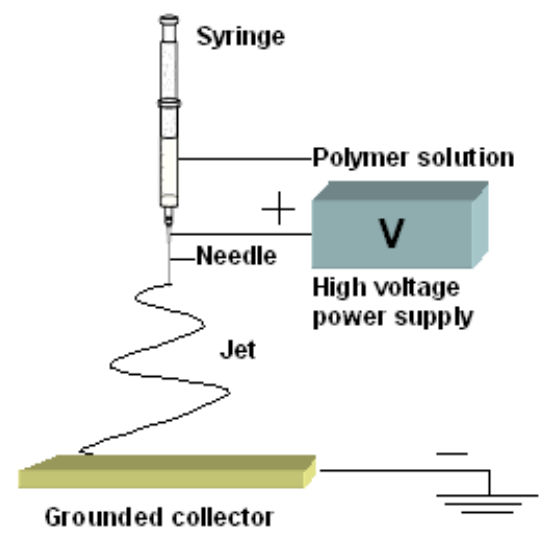

Figure 1-Basic electrospinning set-up

In this work, the effect of the electrospinning process parameters on the morphology of PVB/ $\mathrm{SiO}_{2}$ nanocomposite fibers was analysed.

Woven fabrics produced from high tenacity fibres are used in ballistic protection due to their low density, high strength and high energy absorption capacity. These properties are extremely important for a bullet-fabric interaction which is a complex phenomenon.

The higher kinetic energy of bullet mass and speed during ballistic impact generates more deformation of the fabric. When the bullet speed remains within the limits, the bullet is stopped inside the fabric and the deformation formed on the fabric spreads outwards with the degree of deformation 
which depends on the fabric structure. In contrary, when the bullet speed exceeds a certain maximum, the bullet passes through the fabric. Fabric layers have a restricted energy absorption capacity and it is necessary to develop different structures of them to block the bullet when its kinetic energy exceeds fabric energy absorption limits $[6,7]$. In the work, the $p$-aramid/PVB/AMEO-30 wt. $\% \mathrm{SiO}_{2}$ hybrid composite system was made for this function.

Ceramics have usually been used as reinforcement in the body armour owing to its properties, such as introducing flexibility and light weight of the overall fabric structure [8]. The addition of the nanoscale ceramic reinforcement to polymer matrices improves the mechanical properties, notably compared to the pure matrix material in the body armour [9]. Among this ceramics, nanosilica is one of the primary nanofillers used in polymer composites. The silica nanoparticles are defined by their high specific surface area and due to their collective agglomeration, silane coupling agents modify nanosilica surface for their successful dispersion and deagglomeration, causing the formation of chemical bonds between them and organic components $[9,10]$.

Fiber reinforced composites present impressive engineering materials nowadays. They have their common use in aerospace, automobile, building and military industries. Despite their versatility and great advantages, composites possess certain imperfections and failure properties. Fiber or matrix crackings, as well as delaminations, are common accidents which do not appear in uniform materials [11]. Composite structures are exposed to different impact loading conditions and when they are not fabricated properly, they can undergo a great failure.

It is assumed that impact phenomenon could be divided into four categories according to the impact velocity. Thus, there exist low $(<0.25 \mathrm{~km} / \mathrm{s})$, medium $(0.25-2 \mathrm{~km} / \mathrm{s})$, ballistic $(2-12 \mathrm{~km} / \mathrm{s})$ and hyper velocity impacts (>12 km/s) [12].

There are two forms of impact damages on composite structures - complete penetration of the laminate by high-velocity ballistic strikes and nonpenetrating impacts by low-velocity strikes [13]. With a low velocity impact loading conditions, the time of contact between a projectile and a target is considerably long and the load history can be detected with important information about damage progression [14]. During the impact process, the effect of transverse shear and thickness deformations are significant. Delamination appears among the layers, because of insufficient interlaminar bonding which causes a drop in the shear strain that is greater than the bending strain as a result of deformations in the layers [15]. A low speed impact produces local, micro cracks of a matrix material.
This does not consequently lead to a fracture appearance; though it will produce redistribution of the stress and energy concentrations at the interlaminar sections. In these zones, there is a large diversity in material stiffness which generates a fracture growth due to inter-ply delamination [16, 17]. The total impact energy represents a sum of crack initiation energy and crack propagation energy. The fragile materials possess high values of the crack initiation energy and low values of the crack propagation energy, while with the toughest materials it is completely opposite [18].

Carbon nanotubes (CNTs) possess light weight and excellent energy absorption capacity and thus are applied in producing antiballistic materials for bulletproof vests, body and vehicle armor and body armor which can withstand high bullet speed [19, 20]. Pristine CNTs are usually not well dispersed in polymer matrices owing to the strong Van der Waals attractive forces between the nanotubes which tend to their aggregation. A small quantity of CNTs in polymer matrices is more easily dispersed and it is assumed that the modulus is enhanced. On the contrary, when the amount of CNTs is large, the nanotubes may interact and form small aggregates, which reduce the interfacial contact area for stress transfer in the polymer matrix [21]. In order to prevent from the agglomeration due to the presence of the Van der Waals forces between the nanotubes, compatibility with the polymer matrix can be achieved by chemical modification of CNTs with solvents, surfactants, strong acids, noncovalent and covalent bonding and other chemical methods [22-24].

In the current study, the mechanical and impact properties of hybrid thermoplastic composites were tested. The samples of Colon fabrics were impregnated with poly (vinyl butyral)/ethanol solution, and the AMEO silane surface modification of one sample improved the properties besides the addition of multiwalled carbon nanotubes.

\section{EXPERIMENTAL}

\section{Materials}

For preparation of PVB solution in all three cases, a polymer powder, poly (vinyl butyral) (Mowital $\mathrm{B} 60 \mathrm{H}$, Kuraray Specialities Europe) and absolute ethanol (Zorka Pharma, Šabac) were used. The silica nanoparticles with an average particle diameter of about $7 \mathrm{~nm}$ (Evonik-Degussa, Aerosil 380) were introduced into the PVB solution. The modification of silica nanoparticles was managed with Y-aminopropyl triethoxysilane (AMEO silane). Multiaxial aramid fabrics (Martin Ballistic Mat, Ultratex, Serbia) were used with $p$-aramid fiber type Twaron (Teijin Aramid). For the impact testing, the carbon nanotubes, MWCNT (Cheap Tubes Inc, USA), were put into the PVB solution. The dimensions of 
the nanotubes were from $3 \mu \mathrm{m}$ to $30 \mu \mathrm{m}$ in their length and from $13 \mathrm{~nm}$ to $18 \mathrm{~nm}$ in their outer diameter. Multiaxial aramid fabrics (Martin Ballistic Mat, Ultratex, Serbia) were used with $p$-aramid fiber type Colon (Heracron, Kolon Industries, Inc, Korea) which were impregnated with polyurethane (Desmopan, Bayer) [8]. The dimensions of the fabric sample were $15 \mathrm{~cm} \times 15 \mathrm{~cm}$, and their thickness was around $2 \mathrm{~mm}$.

\section{PREPARATION OF THE SAMPLES}

The silica nanoparticles were put into the PVB solution (10 wt.\%) and stirred continuously for 24 hours and afterwards ultrasonically dispersed in the solution for 15 minutes afterwards. The PVB solutions without the silica particles as well as with them (all with different contents) were tested by changing applied voltages and flow rates in the electrospinning process. A set of experiments was driven with the applied voltages of $16,20,24,28$ and $30 \mathrm{kV}$ while the flow rate was kept constant $\mathrm{Q}$ $=1 \mathrm{~mL} / \mathrm{h}$. Another experimental set was performed with flow rates valued $0.2,0.4,0.6$ and $0.8 \mathrm{~mL} / \mathrm{h}$ while the voltage was held at $\mathrm{V}=20 \mathrm{kV}$. During the electrospinning process, the formed fibers were deposited onto the flat aluminium foil which served as a collector. The distance between the needle tip and the collector was $\mathrm{h}=10 \mathrm{~cm}$ in all cases.

Three pieces of $p$-aramid fabrics (fiber type Twaron) were coated with the PVB solution and the produced $\mathrm{PVB}-\mathrm{SiO}_{2}$ fibers were deposited continuously onto the fabrics during the electrospinning process (Figure 2). The dimensions of each fabric were $29.7 \mathrm{~cm} \times 21 \mathrm{~cm}$, weighing $40 \mathrm{~g}$ approximately. The fibers contained $18 \mathrm{~g}$ of PVB powder and $9 \mathrm{~g}$ of silica nanoparticles (both of them were in 10 wt.\% PVB/ethanol solution) and they were deposited onto the aramid fabrics. The flow rate of the $\mathrm{PVB}-\mathrm{SiO}_{2}$ solution for this process was $\mathrm{Q}=50 \mathrm{~mL} / \mathrm{h}$ and the voltage was held at $\mathrm{V}=30 \mathrm{kV}$, Figure 2 .

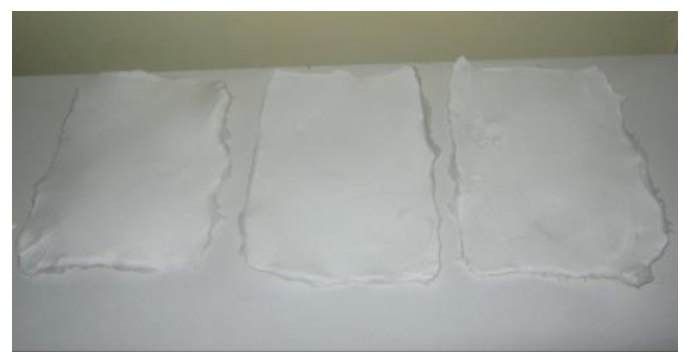

Figure 2 - The coated aramid fabrics with deposited PVB-SiO2 fibers

The aramid fabrics with the deposited PVB$\mathrm{SiO}_{2}$ fibers were hot compressed using $\mathrm{N} 840 \mathrm{D}$ Hix Digital Press (Hix, Corp., USA) at a temperature of $170{ }^{\circ} \mathrm{C}$ for 30 minutes under pressure of 4 bar. The fabrics were additionally pressed with $\mathrm{P}$ 125 press $\left(170{ }^{\circ} \mathrm{C}, 10.6 \mathrm{MPa}\right)$ for 2 hours and then brought under pressure of $20.6 \mathrm{MPa}$ for 1 hour.
For the ballistic properties, the multiaxial aramid fabrics (Martin Ballistic Mat, Ultratex, Serbia) with $p$-aramid fiber type Twaron (Teijin Aramid) were tested. The modification of silica nanoparticles with $\mathrm{y}$-aminopropyl triethoxysilane (AMEO silane, $\left.\left(\mathrm{C}_{2} \mathrm{H}_{5} \mathrm{O}\right)_{3} \mathrm{SiC}_{3} \mathrm{H}_{6} \mathrm{NH}_{2}\right)$ began with adding the silane into $95 \mathrm{wt} . \%$ ethanol- $5 \mathrm{wt} . \%$ water mixture in order to reach a 2 wt.\% final AMEO concentration. The process of hydrolysis and silanol formation needed about 10 minutes. The solution was homogenized with a magnetic stirrer for 30 minutes after the addition of the nanoparticles. After three hours of sonication, the solution was centrifuged for 30 minutes at a speed of $3000 \mathrm{rpm}$. After the centrifugation, the particles were placed at the bottom of the beaker and the supernatant was decanted. In the end, the particles were rinsed with ethanol and dried in an oven at $110^{\circ} \mathrm{C}$ [8].

The modified silica nanoparticles were with an average particle diameter of about $7 \mathrm{~nm}$ and they were added into $10 \mathrm{wt} . \% \mathrm{PVB} / \mathrm{ethanol}$ solution. All the fabrics were coated with $Y$-aminopropyl triethoxysilane (AMEO silane)/ethanol solution, and then left to stand for about 24 hours for ethanol evaporation. Then, two of the fabrics were coated with poly (vinyl butyral) (PVB)/ethanol solution while the other two were coated with the same solution but with the addition of 30 wt.\% AMEO silane modified silica nanoparticles and all of them were left to stay for 24 hours for the ethanol evaporates.

The hard composite samples were hot-pressed using N 840 D Hix Digital Press (Hix, Corp., USA) at a temperature of $170{ }^{\circ} \mathrm{C}$ and under pressure of 4 bars for 60 minutes. The fabrics were further pressed with $\mathrm{P}-125$ press $\left(170^{\circ} \mathrm{C}, 8.2 \mathrm{MPa}\right)$ for 30 minutes. Within the flexible samples, the flexible composite fabrics were stitched together with the lightweight polyester thread (Korteks, Turkey). The two hard pressed samples contained 17 pieces of fabrics, while the flexible ones consisted of 16 layers of fabrics.

For the impact testing, the $10 \mathrm{wt} . \% \mathrm{PVB} /$ ethanol solution was used for the experiments. The MWCNT were firstly added into ethanol with concentration of 0.5 and 1.0 wt.\%, where MWCNT/ PVB ratio was 0.005 and 0.01 , respectively. This ethanol-MWCNT solution was ultrasonicated for 30 minutes separately in order to provide satisfying dispersion of the carbon nanotubes. After this process, the ethanol-MWCNT mixture was added into the 20 wt.\% PVB/ethanol solution due to producing a 10 wt.\% solution which was mixed on/in a magnetic stirrer overnight. The good dispersion of MWCNT in PVB/ethanol solution was achieved and thus the modification of the nanotubes was not needed while the surface modification of Colon fabrics was applied for some samples. 
There were three series of composites which consisted of four pieces of fabrics. The compositions of the samples are presented in Table 1. For the third sample (Colon/AMEO/PVB/1 wt.\% MWCNT), the fabric was firstly impregnated with AMEO silane/ethanol solution owing to the surface modification. The modification of this composite was managed by impregnation with 2 wt. $\%$ AMEO silane/ethanol solution. After the impregnation, the fabrics were left to dry for 24 hours and the appropriate $\mathrm{PVB} / \mathrm{ethanol}$ solution was coated on the fabrics. The solution consisted of $72 \mathrm{~g}$ of ethanol and $8 \mathrm{~g}$ of PVB and appropriate MWCNT concentration $(0,0.5$ or $1.0 \mathrm{wt} \%)$. Both sides of all the three samples were impregnated with the appropriate solutions, after which they were left to stay for 24 hours for ethanol evaporation. The samples were processed in the compress machine (N $840 \mathrm{D}$ Hix Digital Press) under a pressure of 3 bars for 30 minutes and at a temperature of $170{ }^{\circ} \mathrm{C}$.

Table 1 - The composition of the samples for the impact testing

\begin{tabular}{|c|l|}
\hline Sample no. & \multicolumn{1}{|c|}{ Composition } \\
\hline 1 & Colon/PVB \\
\hline 2 & Colon/PVB/1 wt.\% MWCNT \\
\hline 3 & Colon/AMEO/PVB/1 wt.\% MWCNT \\
\hline
\end{tabular}

\section{Characterisation}

The electrospinning apparatus used for the experiments in this work is the Electrospinner $\mathrm{CH}-01$ (Linari Engineering) which is located at the Faculty of Technology and Metallurgy in Belgrade, Figure 3.

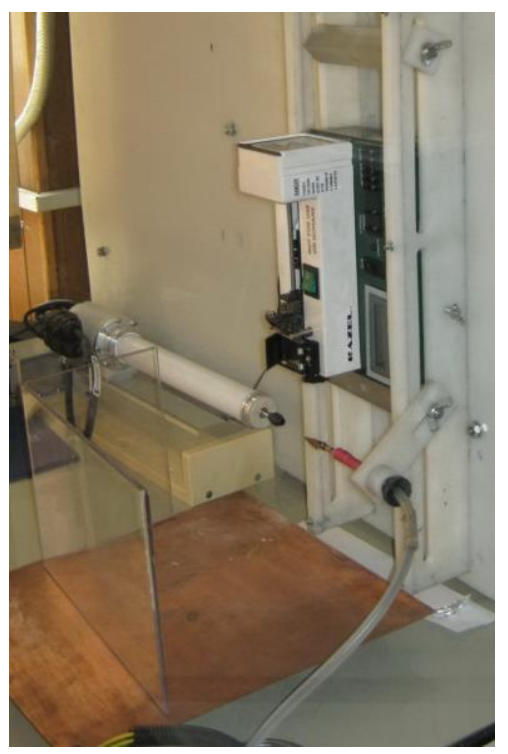

Figure 3 - The electrospinning apparatus at the Faculty of Technology and Metallurgy, Belgrade
The resistance test of the ballistic impact was performed in accordance with the modified ballistic resistance of the personal body armor NIJ standard 0101.04, by applying integrated range instrument system (IRIS) by SABRE ballistics UK [25].

Two types of bullets were used for the ballistic testing: the 357 Magnum FMJ $10.2 \mathrm{~g}$ and the 44 Rem. Magnum JHP $15.6 \mathrm{~g}$, with nominal masses of $10.2 \mathrm{~g}$ and $15.6 \mathrm{~g}$, correspondingly. The first four shots for each sample were fired with the $357 \mathrm{Mag}$ num and the 44 Rem Magnum was used for the fifth one, all of them being shot at a reference velocity of $436 \mathrm{~m} / \mathrm{s}$ for each sample as a target. There were fifteen shots altogether during the ballistic test: twelve with the 357 Magnum and three with the 44 Rem Magnum.

The digital ruler with nonius PRO-Max (Fowler) was used for the measuring of the shots' penetration depths. The print and penetration depth image analysis of the shots were performed in Image ProPlus software. The images were converted to the grayscale mode, and further subjected to the bitmap analyses. The created images were calculated in pixels and converted to millimeters in order to complete 3D image analysis of the penetration depth.

The specimens for the impact tests had a square shape, with the dimensions of $6 \mathrm{~cm} \times 6 \mathrm{~cm}$ and the thickness of about $2 \mathrm{~mm}$. The impact tests were conducted on a high speed puncture impact testing machine Hydroshot HITS-P10 Shimadzu, Japan. The diameter of the striker of the impact testing device was $12.7 \mathrm{~mm}$ while the puncture velocity was $2 \mathrm{~m} / \mathrm{s}$, and the experiment was carried out at room temperature. The impact tests were run due to the determination of impact force and impact absorbed energy. The impact testing equipment used in this work is presented in Figure 4.

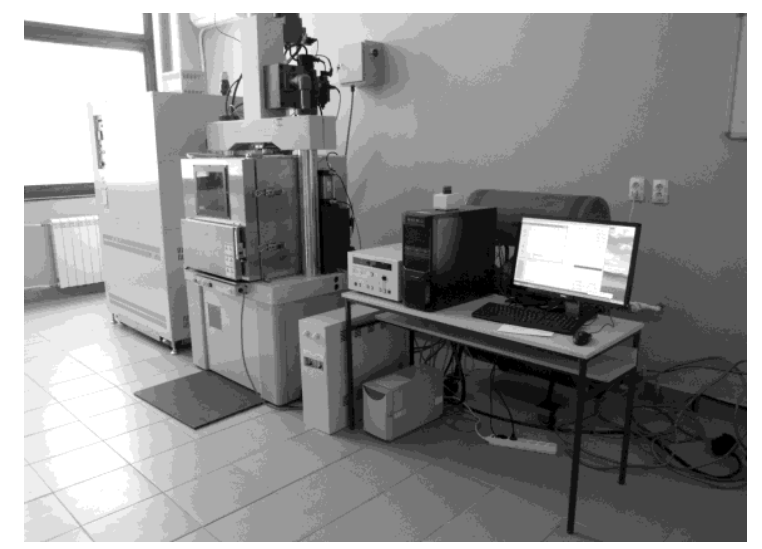

Figure 4 - Overall equipment for the high speed impact tester

\section{RESULTS AND DISCUSSION}

\section{Electrospinning results}

The average diameters of the electrospun fibers from the optical microscopy images ranged from 1.14 to $2.93 \mu \mathrm{m}$. It was observed that some 
fibers had a diameter smaller than $500 \mathrm{~nm}$ and they were visible only by the SEM images. The images showed that, in some cases, the fibers tended to stay close to each other. Probably, the main reason for this was the insufficient working distance $h$. All the formed fibers were mainly narrow at lower voltages of $16 \mathrm{kV}$ and $20 \mathrm{kV}$. Oppositely, the electrospun fibers started to remain whipped while increasing the applied voltages from 24 to $30 \mathrm{kV}$. The whipped fiber structure was also obtained by reducing the flow rate.

The fibers of the PVB solution showed an expected tendency of decreasing their diameters at increasing the applied voltages (Table 2). The maximal value of the average fiber diameter is produced with $\mathrm{Q}=1 \mathrm{~mL} / \mathrm{h}, \mathrm{V}=20 \mathrm{kV}$, and the minimal one is obtained by $\mathrm{Q}=0.8 \mathrm{~mL} / \mathrm{h}, \mathrm{V}=20 \mathrm{kV}$ process parameters [26].

Table 2 - Average fiber diameters of the PVB solution with different process parameters

\begin{tabular}{|c|c|c|}
\hline Flow rate & Applied voltage & Average diameter \\
\hline$Q, \mathrm{~mL} / \mathrm{h}$ & $V, \mathrm{kV}$ & $d_{\text {avg }}, \mu \mathrm{m}$ \\
\hline 0.2 & 20 & 1.67 \\
\hline 0.4 & 20 & 1.68 \\
\hline 0.6 & 20 & 1.54 \\
\hline 0.8 & 20 & 1.46 \\
\hline 1 & 16 & 2.13 \\
\hline 1 & 20 & 2.94 \\
\hline 1 & 24 & 2.08 \\
\hline 1 & 28 & 1.88 \\
\hline 1 & 30 & 1.77 \\
\hline
\end{tabular}

According to the studies [27-29], the PVB composite fibers with a great content of $50 \mathrm{wt} . \%$ $\mathrm{SiO}_{2}$ nanoparticles were deposited on $p$-aramid fabrics which had been impregnated with the PVB solution. Figure $5 \mathrm{a}$ shows the temperature dependence of the storage modulus for the $p$-aramid fabric with PVB film and the $p$-aramid fabric with PVB/PVB-50 wt.\% $\mathrm{SiO}_{2}$ fibers. The composite $p$ aramid/PVB showed a lower value of the storage modulus at the temperatures of $40{ }^{\circ} \mathrm{C}$ and $70{ }^{\circ} \mathrm{C}$. The difference in the two storage moduli was greater when the temperature was increased (Table 3). The glass transition temperature of the $p$-aramid/PVB/PVB-50 wt. $\% \mathrm{SiO}_{2}$ fibers composite was $76.4{ }^{\circ} \mathrm{C}$, about $8{ }^{\circ} \mathrm{C}$ higher that the $p$-aramid/PVB composite, Table 3. Tan Delta of the $p$ aramid/PVB/PVB-50 wt.\% $\mathrm{SiO}_{2}$ fibers composite had a lower value which indicated that the addition of the PVB fibers with silica nanoparticles promote enhanced thermal properties of the $p$-aramid fabrics, Table 3, Figure $6 \mathrm{~b}$, which was the aim of the addition of the composite fibers. The mechanical properties were slightly improved, but insufficiently due to the weak bonds among $p$-aramid fabric, PVB and silica nanoparticles.

Table 3 - DMA results for $p$-aramid fabrics

\begin{tabular}{|l|c|c|c|c|}
\hline \multicolumn{1}{|c|}{ Sample } & $\begin{array}{c}\mathrm{E}^{\prime}(\mathrm{MPa}) \\
40^{\circ} \mathrm{C}\end{array}$ & $\begin{array}{c}\mathrm{E}^{\prime}(\mathrm{MPa}) \\
70^{\circ} \mathrm{C}\end{array}$ & $\begin{array}{c}\mathrm{T}_{\mathrm{g}} \\
\left({ }^{\circ} \mathrm{C}\right)\end{array}$ & $\begin{array}{c}\tan \\
\delta\end{array}$ \\
\hline$p$-aramid & 2230 & 567 & 68.6 & 0.37 \\
\hline $\begin{array}{l}p \text {-aramid/50 wt. } \\
\% \mathrm{SiO}_{2} \text { fibers }\end{array}$ & 2336 & 1355 & 76.4 & 0.36 \\
\hline
\end{tabular}

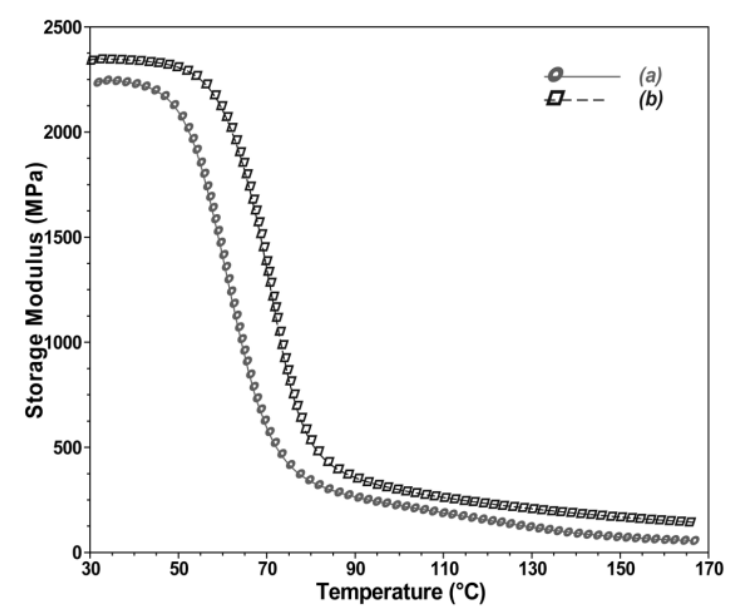

Figure 5 - Storage modulus of: (a) p-aramid/PVB fabrics and (b) $p$-aramid/PVB fabrics with $\mathrm{PVB} / \mathrm{SiO}_{2}$ nanofibers

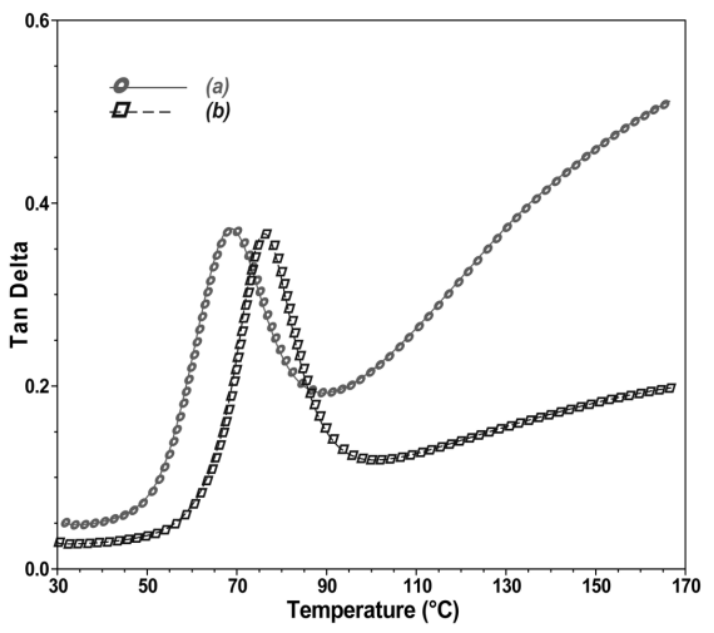

Figure 6 - Tan Delta (tan $\delta$ ) of: (a) $p$-aramid/PVB fabrics and (b) $p$-aramid/PVB fabrics with $\mathrm{PVB} / \mathrm{SiO}_{2}$ nanofibers

The $\mathrm{SiO}_{2}$ nanoparticles were then modified with AMEO silane. Based on the images of the electrospun fibers with unmodified silica nanoparticles, it was evident that these nanoparticles fused into big aggregates, Figure 7, scale bar $10 \mu \mathrm{m}$. Unlike them, the modified nanoparticles were welldistributed inside the fibers, Figure 8, scale bar 10 $\mu \mathrm{m}$. 


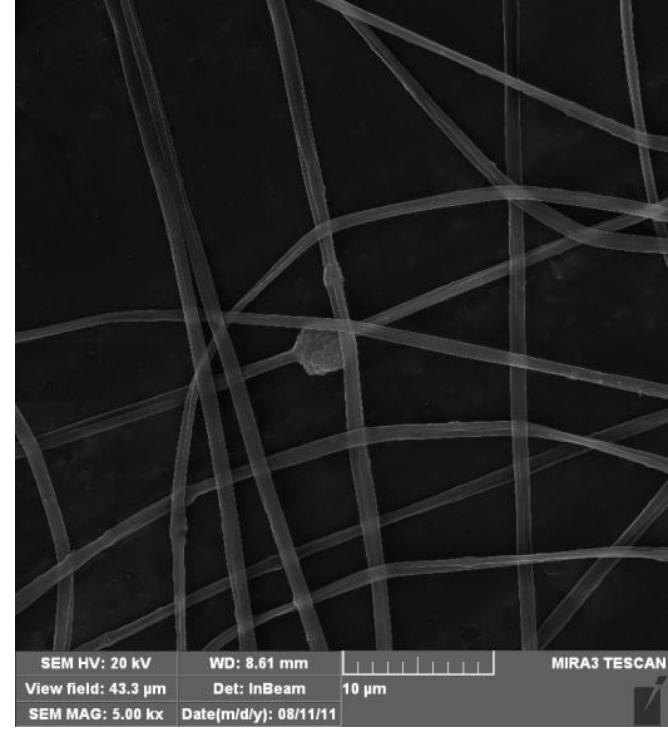

Figure 7 - SEM image of the PVB fibers with 5 wt. \% unmodified $\mathrm{SiO}_{2}$ nanoparticles $(Q=1 \mathrm{~mL} / \mathrm{h}, V=30 \mathrm{kV})$

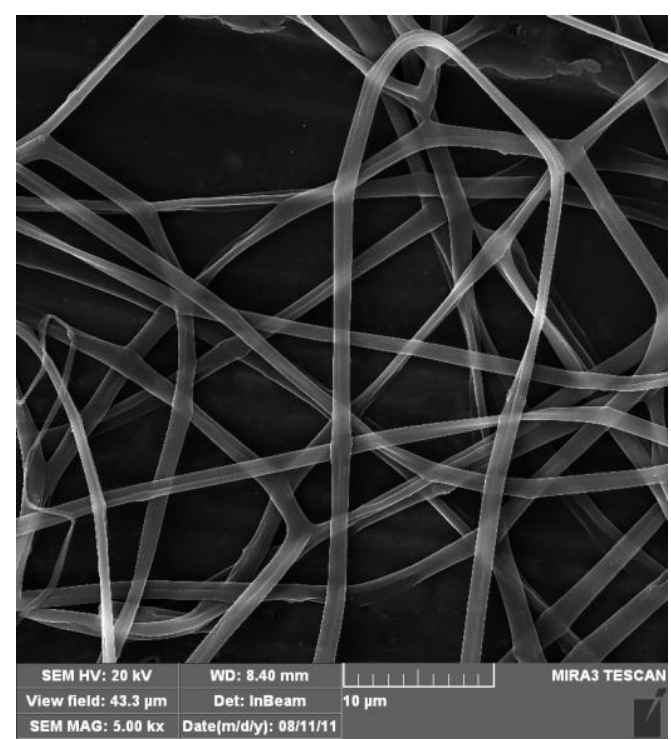

Figure 8 - SEM image of the PVB fibers with 5 wt.\% modified $\mathrm{SiO}_{2}$ nanoparticles

$$
(Q=1 \mathrm{~mL} / \mathrm{h}, \mathrm{V}=30 \mathrm{kV})
$$

\section{Ballistic properties results}

Dynamic mechanical properties of the three hybrid composites, $p$-aramid/PVB, $p$-aramid/PVB (5 wt. $\% \mathrm{SiO}_{2}$ ) and $p$-aramid/PVB/AMEO (5 wt. \% $\mathrm{SiO}_{2}$ ) samples were investigated. The samples consisted of four pieces of $p$-aramid fabrics, fiber type Twaron. The storage modulus vs. temperature dependencies are shown in Figure 9. The addition of AMEO-modified silica nanoparticles maximized the storage modulus of the $p$-aramid/PVB/AMEO-5 wt. $\% \mathrm{SiO}_{2}$ composite, where the value of the storage modulus was $2983 \mathrm{MPa}$, compared with the value of the $p$-aramid/PVB composite which was $1916 \mathrm{MPa}$. The modification of the nano- particles with AMEO silane made the chemical bonds between the $\mathrm{SiO}_{2}$ nanoparticles, polymers and $p$-aramid fibers, producing significant increase in the mechanical properties of the $p$-aramid/ /PVB/AMEO-5 wt. \% $\mathrm{SiO}_{2}$ composite. This modification also led to improved dispersion of the silica nanoparticles and therefore enhanced the mechanical properties of the composite [8].

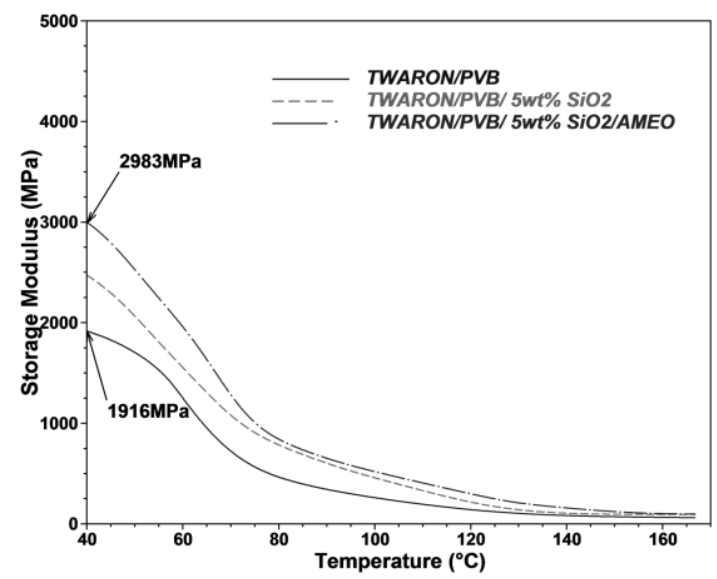

Figure 9 - Storage modulus of the samples

Due to the previous results, the two samples which were used for the bullet shooting tests contained only AMEO modified silica nanoparticles. The ballistic results are presented in Table 4 . The samples are denoted as follows: No. 1- 17 pieces of fabrics with PVB - hard option; No. 2- 17 pieces of fabrics with PVB and 30 wt.\% AMEO silane modified silica nanoparticles-hard option; No. 3- 16 pieces of fabrics with PVB-flexible option; No. 4- 16 pieces of fabrics with PVB and 30 wt.\% AMEO silane modified silica nanoparticles-flexible option. The sample No.1 is removed after the first shot due to the complete penetration of the bullet no.1. The provided number of shots is four instead of five for the sample No. 3 because there was no registered velocity for one bullet.

From the Table 4 it is obvious that the 44 Rem. Magnum bullets made a larger penetration depth than the 357 Magnum ones in each sample. This was typical due to the greater mass of the $44 \mathrm{Rem}$. Magnum bullets.

Due to the bullet shooting test it is confirmed that the composites of $p$-aramid/PVB without silica reinforcement could not always serve as full protection against bullets. This is evident from the complete penetration of bullet no. 1 in sample No. 1 with 17 pieces of fabrics, Table 4, Figure 10. For example, shot no. 2 is realised with the 357 Magnum bullet which partially penetrated 17 pieces of fabrics with PVB and 30 wt.\% AMEO silane modified silica nanoparticles, making the indentation depth of $11.65 \mathrm{~mm}$, Table 4). Also, all the other shots produced partial penetrations of the bullets. The introduction of AMEO silane modified silica 
nanoparticles in the composite of $p$-aramid/ poly(vinyl butyral) provided significant improvement in the mechanical properties, producing hybrid ballistic system of higher protection, Figure 11.

Table 4 - Results of bullet-shooting test

\begin{tabular}{|c|c|l|c|}
\hline $\begin{array}{c}\text { No. of } \\
\text { sample }\end{array}$ & $\begin{array}{c}\text { Shot } \\
\text { No. }\end{array}$ & \multicolumn{1}{|c|}{ Type of bullet } & $\begin{array}{c}\text { Indentation } \\
\text { depth }(\mathrm{mm})\end{array}$ \\
\hline 1 & 1 & 357 Magnum & $\begin{array}{c}\text { complete } \\
\text { penetration }\end{array}$ \\
\hline 2 & 2 & 357 Magnum & 11.65 \\
2 & 3 & 357 Magnum & 12.9 \\
2 & 4 & 357 Magnum & 21.5 \\
2 & 5 & 357 Magnum & 15.7 \\
2 & 6 & 44 Rem. Magnum & 21.85 \\
\hline 3 & 7 & 357 Magnum & 7.9 \\
3 & 8 & 357 Magnum & 10 \\
3 & 9 & 357 Magnum & 11.3 \\
3 & 10 & 44 Rem. Magnum & 16.6 \\
\hline 4 & 11 & 357 Magnum & 11.5 \\
4 & 12 & 357 Magnum & 7.2 \\
4 & 13 & 357 Magnum & 9.4 \\
4 & 14 & 357 Magnum & 11 \\
4 & 15 & 44 Rem. Magnum & 19.9 \\
\hline
\end{tabular}

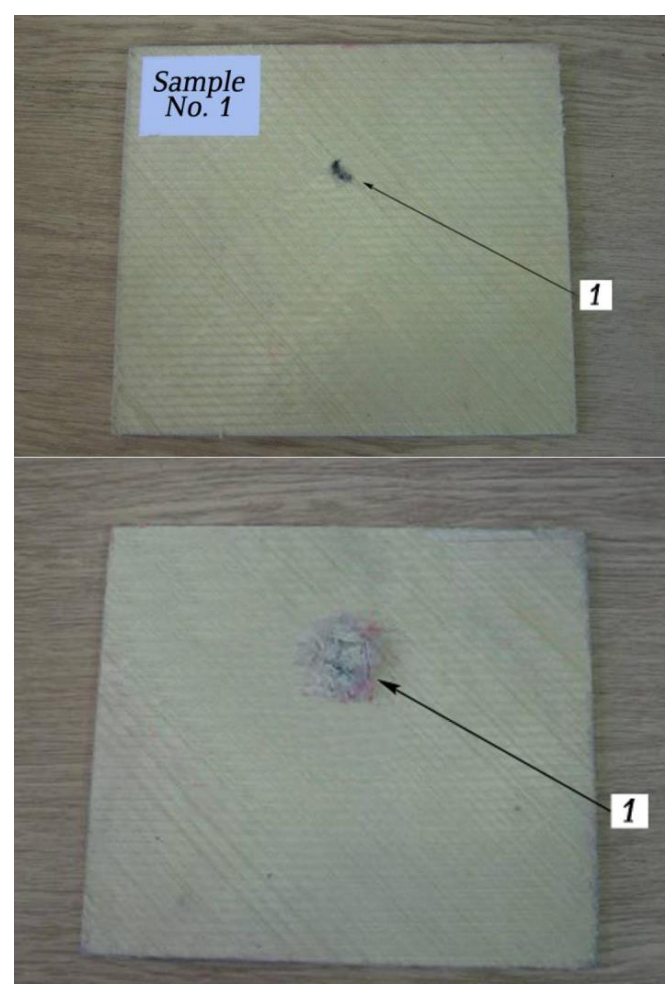

Figure 10 - Front and back side of shot sample No. 1

The magnum bullet no.1 completely penetrated the sample No.1, with the thickness of $8.2 \mathrm{~mm}$. The millimeter scales analysis of the entrance print of this shot is illustrated in Figure 12. A proper 3D graph image of a penetration depth is depicted in Figure 13.

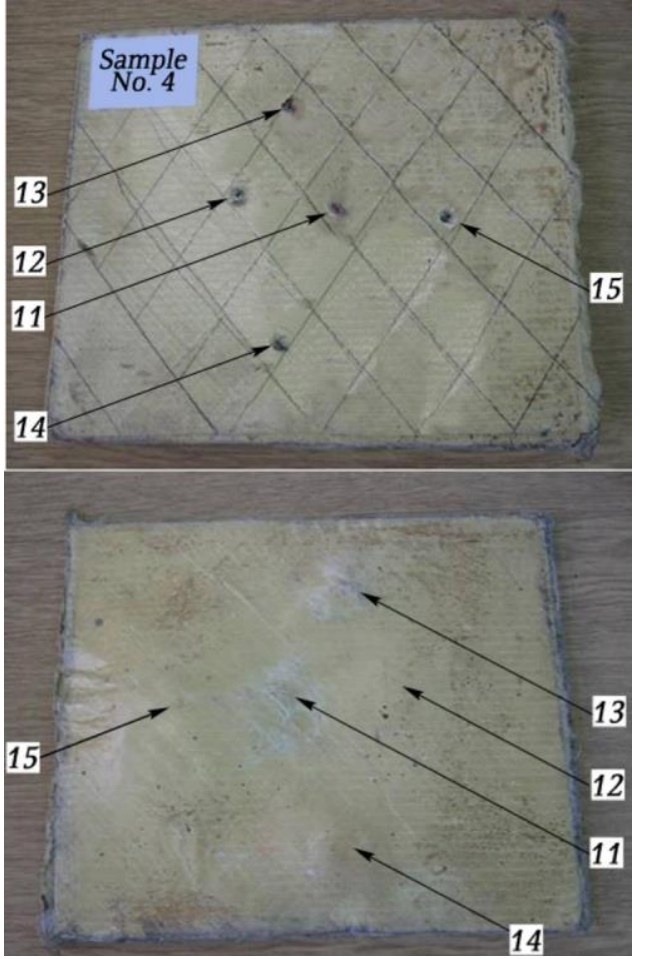

Figure 11 - Front and back side of shot sample No. 4

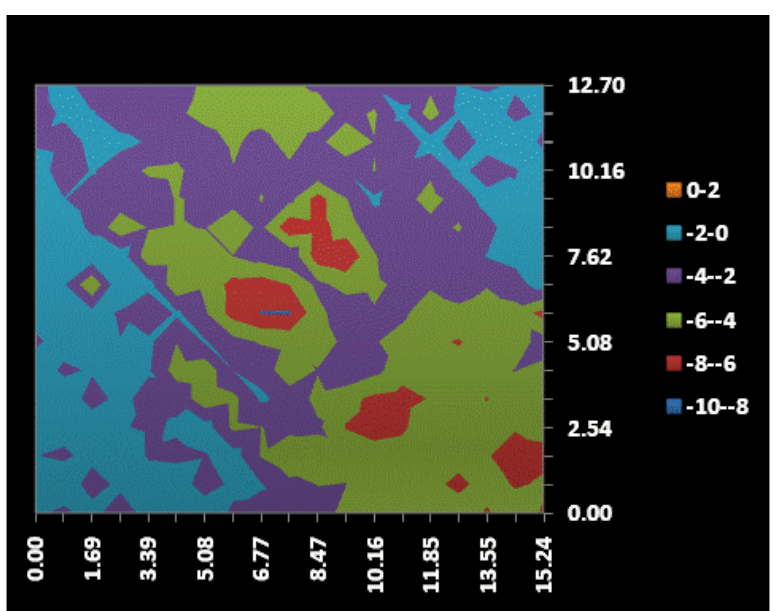

Figure 12 -Print analysis of the shot No. 1

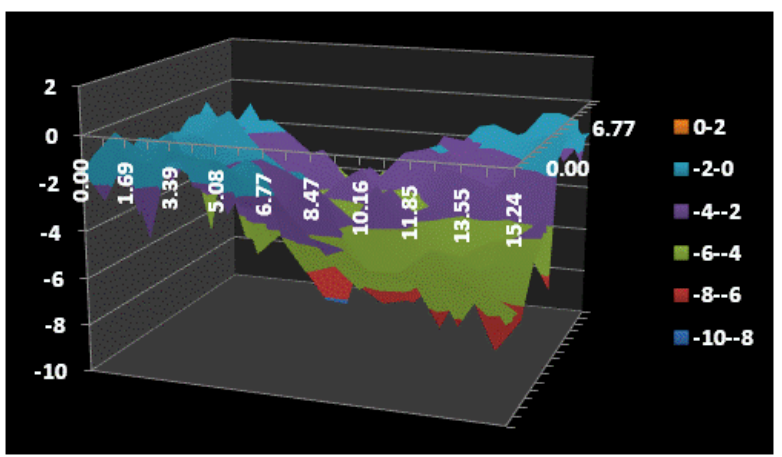

Figure 13 - Indentation depth analysis of the shot No. 1

The sample No.2-hard option had a lower value of the storage modulus (368.4 MPa) compared to the sample No.4 (the flexible option) which was 
769.3 MPa due to a process of delamination in the hard sample. Tan $\delta$ of the sample No. 2 had a lower value compared to the sample No.4, owing to the weak bonds among $p$-aramid, $\mathrm{PVB}$ and $\mathrm{SiO}_{2}$ nanoparticles. With glass transition temperature of $\mathrm{T}_{\mathrm{g}, 2}=68.94{ }^{\circ} \mathrm{C}$ which originates in PVB, the hard sample (No. 2) exposed better thermo mechanical properties than the flexible one (No. 4, $\mathrm{T}_{\mathrm{g}, 4}=$ $=64.77^{\circ} \mathrm{C}$ ), due to the compression in the hard option.

\section{Impact tester analysis}

The samples were deformed after the impact process, without the complete penetration, Figures 14 and 15 . The absorbed energy is accountable for the energy spent in producing damage.

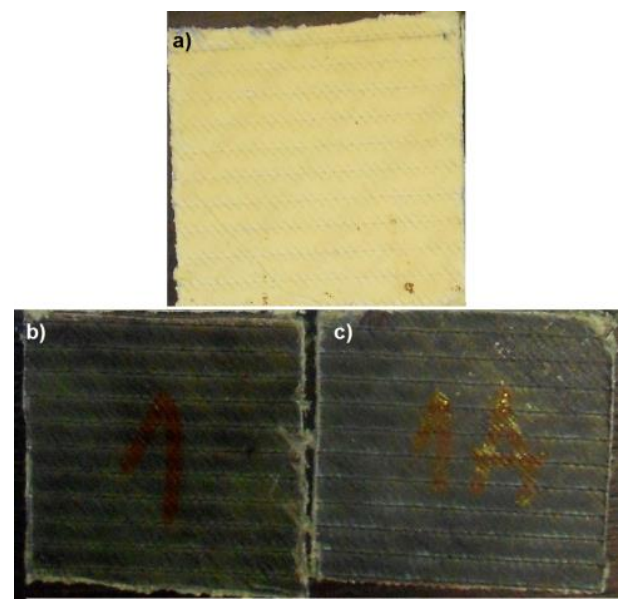

Figure 14 - Samples before the impact test: a) Colon/PVB; b) Colon/PVB/1 wt.\% MWCNT; c) Colon/AMEO/PVB/ 1 wt.\% MWCNT

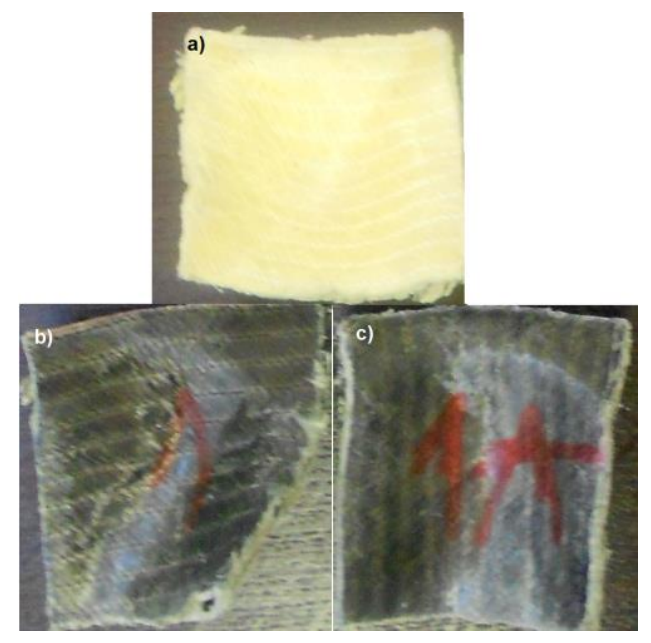

Figure 15 - Samples after the impact test:

a) Colon/PVB; b) Colon/PVB/1 wt.\% MWCNT; c) Colon/AMEO/PVB/ 1 wt.\% MWCNT

The force curve in the impact process performs linearly in the beginning, and this part is defined as an elastic zone with small elastic deformations of the composite. After this segment, the change of the force curve slope appears and with the increase of impact absorbed energy of a striker, the composite begins to endure plastic deformations. Then, the maximum of the impact force occurs $\left(F_{\max }\right)$, with the appropriate absorbed energy $\left(E_{F \max }\right)$. After this point, there is a sudden drop in force and rise of absorbed energy when a process of delamination develops with a failure. At the end of the impact process, the force returns to zero and relevant absorbed energy at this point presents the total absorbed energy $\left(E_{\text {tot }}\right)$ which takes a constant value [12].

The results of DMA analysis exposed that the modulus ( $E^{\prime}$ ) of the Colon/PVB sample increased with the addition of multiwalled carbon nanotubes and surface modification of the fabric (Figure 16). The introduction of MWCNT to the Colon/PVB fabrics increased the storage modulus by $21.2 \%$ for the Colon/PVB/1 wt.\% MWCNT and by $60.1 \%$ for the Colon/AMEO/PVB/1 wt.\% MWCNT sample in comparison with the Colon/PVB respectively, Figure 16, Table 5. These values demonstrate that a good dispersion of MWCNT was achieved and the impregnation of the fabric with AMEO silane maximized the storage modulus for the third sample as a result of the strong bonds between AMEO silane and Colon/PVB surface.

Table 5 - DMA test results for all the samples

\begin{tabular}{|c|c|c|c|}
\hline Sample no. & $\mathrm{E}^{\prime}\left(\mathrm{MPa}, 40^{\circ} \mathrm{C}\right)$ & $\tan \delta 1$ & $\operatorname{Tg}\left({ }^{\circ} \mathrm{C}\right)$ \\
\hline 1 & 1377 & 0.2934 & 65.53 \\
\hline 2 & 1669 & 0.3029 & 66.35 \\
\hline 3 & 2204 & 0.3012 & 69.21 \\
\hline
\end{tabular}

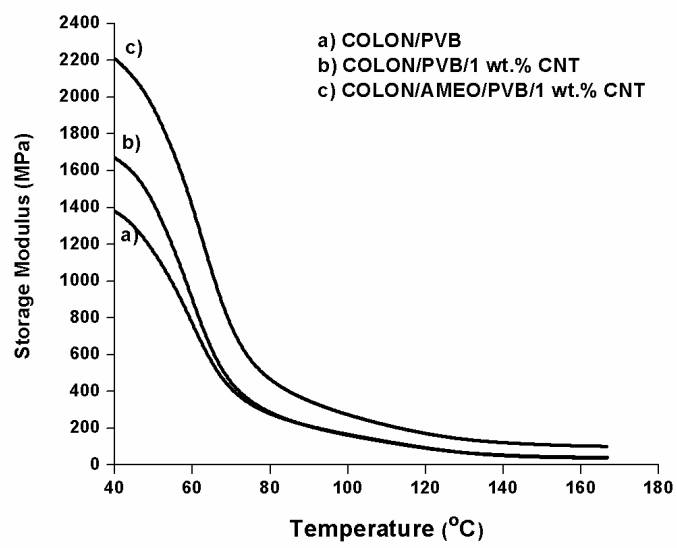

Figure 16 - Storage modulus of the samples

The first peak of Tan Delta shows the glass transition temperature, $T_{g}$, of PVB in the impregnated Colon fabrics. The $T_{g}$ value for the CoIon/PVB sample was $65.53{ }^{\circ} \mathrm{C}$, and the value for 
the Colon/PVB/ 1 wt.\% MWCNT sample was $66.35^{\circ} \mathrm{C}$, Figure 17 , Table 5. For the third sample, after modification with AMEO silane, the storage modulus increased considerably and $T_{g}$ progressed slightly. The value of $\mathrm{T}_{\mathrm{g}}$ for the Colon/AMEO/PVB/1 wt.\% MWCNT was $69.21^{\circ} \mathrm{C}$. Hence, there was a light increase in thermal stability with the addition of MWCNT and modification with AMEO silane which diminished the overall mobility of the polymer chains.

Tan Delta value of these fabrics was almost the same for all the samples at the $T_{g}$ temperature, Table 5, Figure 17. With the rise of temperature, the Tan Delta value of the Colon/AMEO/PVB/1 wt.\% MWCNT sample was decreasing due to the strong bonds among AMEO silane, PVB, MWCNT and polyurethane. The glass transition temperature of polyurethane is about $150{ }^{\circ} \mathrm{C}$.

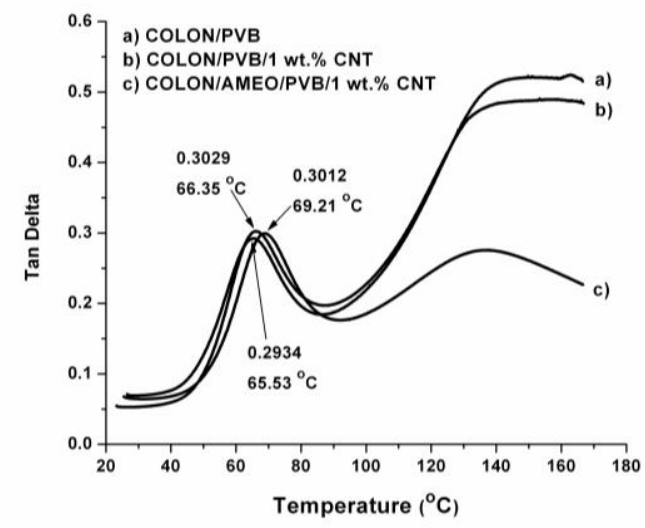

Figure 17 - Tan Delta of the samples

The results of the impact tester analysis are given in Tables 6 and 7. The maximum impact force $\left(F_{\max }\right)$ of the Colon/PVB samples increased with the addition of pure multiwalled carbon nanotubes. According to Table 3, the AMEO modified sample demonstrated the greatest impact force (4.55 kN) compared to the Colon/PVB sample $(3.20 \mathrm{kN})$. The result for the Colon/AMEO/PVB/ 1 wt. $\%$ MWCNT yielded around $42 \%$ improvement in the maximum impact force compared to the Colon/PVB sample.

All the samples had very similar time and displacement for their peak force values, Figures 18 and 19, Table 6.

Table 6 - Impact force test results for all the samples

\begin{tabular}{|c|c|c|c|}
\hline Sample no. & $\begin{array}{c}\text { Time, } \\
(\mathrm{msec})\end{array}$ & $\begin{array}{c}\text { Displacement } \\
(\mathrm{mm})\end{array}$ & $\begin{array}{c}\text { Fmax } \\
(\mathrm{kN})\end{array}$ \\
\hline 1 & 13.66 & 12.11 & 3.20 \\
\hline 2 & 10.47 & 16.11 & 3.64 \\
\hline 3 & 12.43 & 18.75 & 4.55 \\
\hline
\end{tabular}

The slope of the linear part of the force-time curve is proportional to the storage modulus [30]. It increased from the first sample to the third one, with the addition of MWCNT, and AMEO silane surface modification, Figure 18.

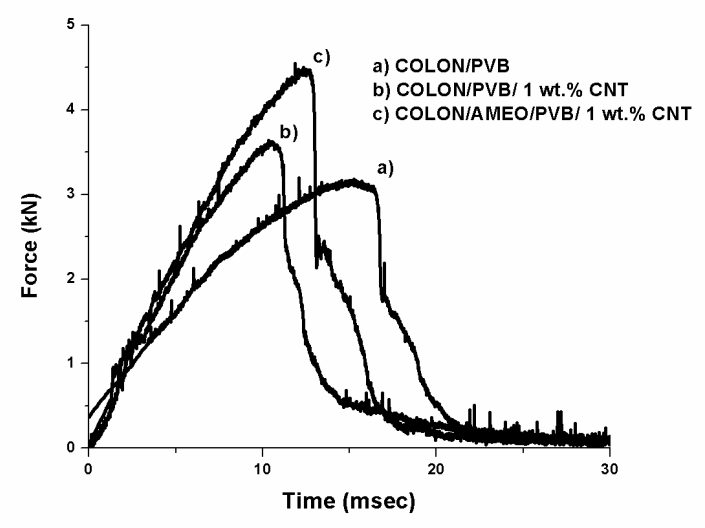

Figure 18 - Force versus time for all the samples

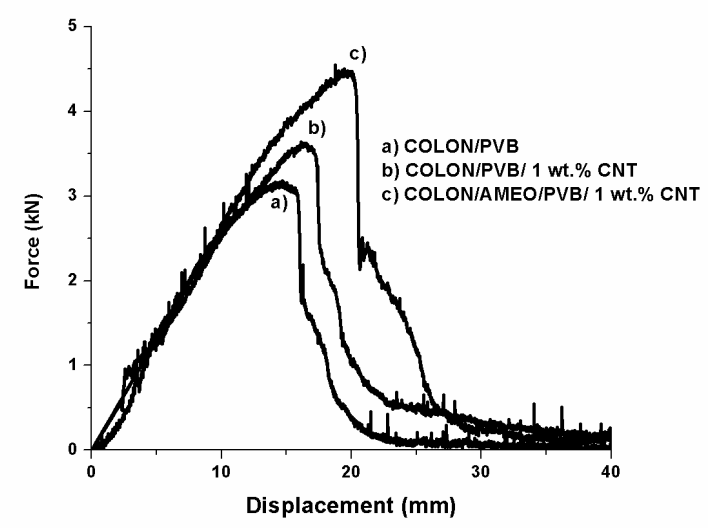

Figure 19 - Force versus displacement for different Colon/PVB fabrics

Similarly to the results for the impact forces, the total absorbed energy of the Colon/PVB samples increased with the addition of pure multiwalled carbon nanotubes, Figures 20 and 21. Also, from Table 7, the AMEO modified sample displayed greater absorbed energy compared to the other two samples. The third sample produced around a $73 \%$ improvement in the total impact energy absorption $(65.69 \mathrm{~J})$ compared to the Colon/PVB sample (37.97 J).

Table 7 - Impact energy test results for all the samples

\begin{tabular}{|c|c|c|}
\hline Sample no. & $\mathrm{E}_{\text {Fmax }}(\mathrm{J})$ & $E_{\text {tot, }}(\mathrm{J})$ \\
\hline 1 & 18.84 & 37.97 \\
\hline 2 & 31.86 & 49.94 \\
\hline 3 & 44.32 & 65.69 \\
\hline
\end{tabular}




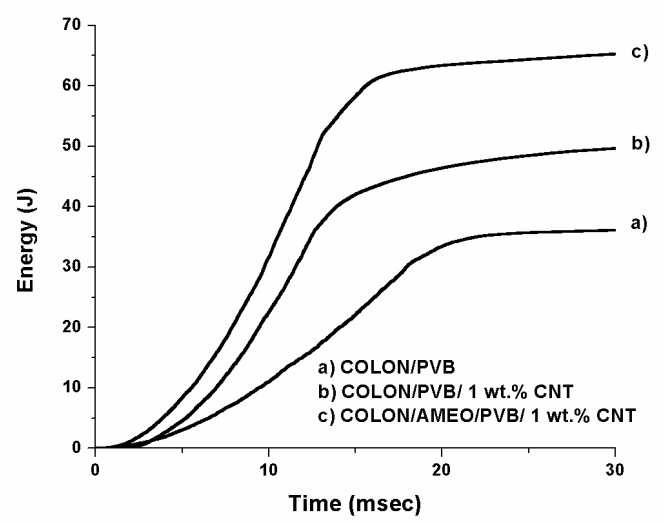

Figure 20 - Energy versus time for all the samples

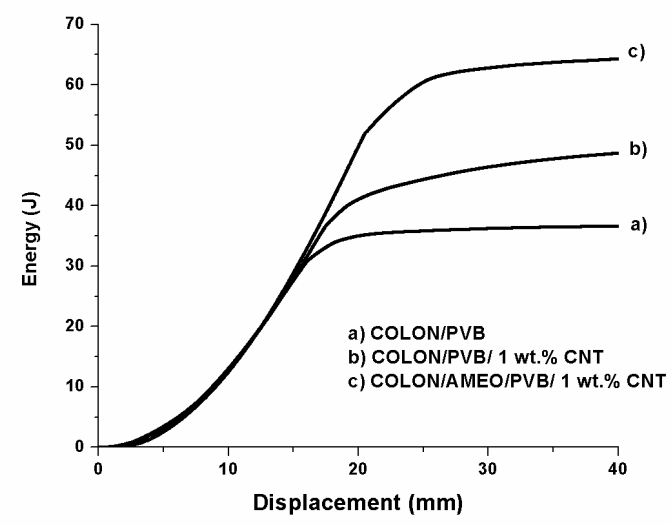

Figure 21 - Energy versus displacement for different Colon/PVB fabrics

The results of the samples from the impact tester analysis were in coherence with the results from DMA analysis and they indicated the effect of the AMEO modification and MWCNT content on the mechanical and impact properties of the composites.

\section{CONCLUSION}

The structure and morphology of the electrospun $\mathrm{PVB} / \mathrm{SiO}_{2}$ composite fibers was investigated by changing two process parameters - the flow rate of the solution $Q$ and the applied voltage $V$, as well as the nanoparticle content and treatment. The produced nanofibers were merely narrow at low voltages of $16 \mathrm{kV}$ and $20 \mathrm{kV}$. However, the fibers began to whip at the voltage of $24 \mathrm{kV}$ and by further increasing, up to $30 \mathrm{kV}$, they were completely coiled.

The addition of the PVB fibers with silica nanoparticles promote enhanced thermal properties of the $p$-aramid fabrics comparing to ones coated with PVB film, producing hybrid ballistic system of higher protection.
The penetration of the samples during the impact test did not occur. The Colon/AMEO/PVB/1 wt.\% MWCNT sample exhibited the increase of storage modulus, impact force and absorbed energy compared to the Colon/PVB sample. The results from DMA analysis were consonant with the ones from impact tester analysis and they demonstrated that the best results for the properties of Colon/PVB sample were achieved with the addition of $1 \%$ wt. concentration of MWCNT and the surface modification with AMEO silane.

\section{Acknowledgements}

The authors wish to acknowledge the financial support from the Ministry of Education, Science and Technological Development of the Republic of Serbia through Projects No. TR 34011 and III 45019 .

\section{REFERENCES}

[1] D. H. Reneker, I. Chun, (1996) Nanometre diameter fibers of polymer, produced by electrospinning, Nanotechnology 7, 216-223.

[2] T. J. Sill, H. A. von Recum, (2008) Electrospinning: Applications in drug delivery and tissue engineering, Biomaterials 29, 1989-2006.

[3] C. Zhang, X. Yuan, L. Wu, Y, Han, J. Sheng, (2005) Study on morphology of electrospun poly (vinyl alcohol) mats, European Polymer Journal 41, 423-432.

[4] K. Garg, G. L. Bowlin, (2011) Electrospinning jets and nanofibrous structures, Biomicrofluidics, 5, 391403.

[5] L. V. Schueren, B. D. Schoenmaker, O. I. Kalaoglu, K. D. Clerck, (2011) An alternative solvent system for the steady state electrospinning of polycaprolactone, European Polymer Journal 47, 1256-1263.

[6] M. Karahan, A. Kus, R. Eren, (2008) An investigation into ballistic performance and energy absorption capabilities of woven aramid fabrics, International Journal of Impact Engineering, 35, 499-510.

[7] R. Aleksić, I. Živković, Dinamičko-mehanička svojstva balističkih kompozitnih materijala, TMF, Beograd, 2009.

[8] H. Mahfuz, F. Clements, V. Rangari, V. Dhanak, G. Beamson, (2009) Enhanced stab resistance of armor composites with functionalized silica nanoparticles, Journal of Applied Physics 105, 293-307

[9] A. M. Torki, D. B. Stojanović, I. D. Živković, A. Marinković, S. D. Škapin, P. S. Uskoković, R. R. Aleksić, (2012) The viscoelastic properties of modified thermoplastic impregnated multi-axial aramid fabrics, Polymer Composites 33, 158-180.

[10] D. Stojanović, A. Orlović, S. B Glišić, S. Marković, V. Radmilović, P. S. Uskoković, R. Aleksić, (2010) Preparation of MEMO silane-coated $\mathrm{SiO}_{2}$ nanoparticles under high pressure of carbon dioxide and ethanol, The Journal of Supercritical Fluids 52, 276-284.

[11] W. A. de Morais, S. N. Monteiro, J. R. M. d'Almeida, (2005) Effect of the laminate thickness on the composite strength to repeated low energy impacts, Composite Structures 70, 223-228.

[12] N. V. Padaki, R. Alagirusamy, B. L. Deopura, B. S. Sugun, R. Fangueiro, (2008) Low velocity impact 
behaviour of textile reinforced composites, Indian Journal of Fibre and Textile Research 33, 189-202.

[13] E. Sevkat, B. Liaw, F. Delale, B. B. Raju, (2010) Effect of repeated impacts on the response of plainwoven hybrid composites, Composites: Part B: Engineering 41, 403-413.

[14] T.-W. Shyr, Y.-H. Pan, (2003) Impact resistance and damage characteristics of composite laminates, Composite Structures 62, 193-203.

[15] G. R. Rajkumar, M. Krishna, H. N. Narasimha Murthy, S. C. Sharma, K. R. Vishnu Mahesh, (2011) Effect of low velocity repeated impacts on property degradation of aluminum-glass fiber laminates, International Journal of Engineering Science and Technology (IJEST) 3, 4131-4139.

[16] D. J. Elder, R. S. Thomson, M. Q. Nguyen, M. L. Scott, (2004) Review of delamination predictive methods for low speed impact of composite laminates, Composite Structures 66, 677-683

[17] G. Belingardi, M. P. Cavatorta, R. Duella, Repeated impact behaviour and damage progression of glass reinforced plastics, Proceedings of the ECF 16 (European Conference on Fracture), (2006).

[18] M. Chircor, R. Dumitrache, L. Dumitrache Cosmin, The Impact Behaviour of Composite Materials, Proceedings of the $3^{\text {rd }}$ International Conference on Maritime and Naval Science and Engineering (2010), 45-50.

[19] K. Mylvaganam, L. C. Zhang, (2007) Ballistic resistance capacity of carbon nanotubes, Nanotechnology 18, 475701.

[20] A. Morka, B. Jackowska, (2011) Ballistic resistance of the carbon nanotube fibres reinforced composites - Numerical study, Computational Materials Science 50, 1244-1249.

[21] M. R Loos, V. Abetz, K. Schulte, (2010) Dissolution of MWCNTs by using polyoxadiazoles, and highly effective reinforcement of their composite films,
Journal of Polymer Science Part A: Polymer Chemistry 48, 5172-5179.

[22] M. M. Tomishko, O. V. Demicheva, A. M. Alekseev, A. G. Tomishko, L. L. Klinova, O. E. Fetisova, (2009) Multiwall carbon nanotubes and their applications, Russian Journal of General Chemistry 79, 19821986.

[23] S. Parveen, S. Rana, R. Fangueiro, (2013) A review on nanomaterial dispersion, microstructure, and mechanical properties of carbon nanotube and nanofiber reinforced cementitious composites, Journal of Nanomaterials ID 710175.

[24] H. Kwon, S. Cho, M. Leparoux, A. Kawasaki, (2012) Dual-nanoparticulate-reinforced aluminum matrix composite materials, Nanotechnology 23, 225704.

[25] Ballistic Resistance of Personal Body Armor, NIJStandard-0101.04, https://www.ncjrs.gov/pdffiles1/nij/183651.pdf.

[26] V. Obradović, A. Kojović, D. B. Stojanović, N. D. Nikolić, I. Živković, P. S. Uskoković, R. Aleksić, (2011) The Analysis of Forming $\mathrm{PVB}^{-\mathrm{SiO}_{2}}$ Nanocomposite Fibers by the Electrospinning Process, Scientific Technical Review 3-4, 34-38.

[27] L. A. Utracki, (2010) In Rigid ballistic composites, NRC Publications Archive: Canada, pp. 45.

[28] M. J. Decker, C. J. Halbach, C. H. Nam, N. J. Wagner, E. D. Wetzel, (2007) Stab resistance of shear thickening fluid (STF)-treated fabrics, Composites Science and Technology 67, 565-578.

[29] Y. S. Lee, E. D. Wetzel, N. J. Wagner, (2003) The ballistic impact characteristics of Kevlar $\AA$ woven fabrics impregnated with a colloidal shear thickening fluid, Journal of Materials Science 38, 2825-2833.

[30] M. Sánchez-Soto, A. B. Martínez, O. O. Santana, A. Gordillo, (2004) On the application of a damped model to the falling weight impact characterization of glass beads-polystyrene composites, Journal of Applied Polymer Science 93, 1271-1284.

\section{IZVOD}

\section{ARAMIDNI KOMPOZITI IMPREGNISANI SA RAZLIČITIM OJAČANJIMA: NANOVLAKNA, NANOČESTICE I NANOCEVI}

U ovom istraživanju su se elektrospinovana vlakna, nanočestice i nanocevi koristili kao ojačanja
koja bi unapredila mehanička svojstva materijala za balističku zaštitu. Uzorci poliuretan/p-
aramidnih multiaksijalnih lamina (Twaron i Kolon lamine) su impregnisani sa poli(vinil
butiral)(PVB)/etanol rastvorom sa različitim sadržajem ojačanja. Radi poboljšanja mehaničkih,
balističkih i impakt svojstava, modifikovala se površina lamina sa $v$-aminopropiltrietoksisilanom
(AMEO silan)/etanol rastvorom i koristile su se silika nanočestice modifikovane AMEO silanom.
Ovaj rad je podeljen na tri dela istraživanja: proces elektrospininga, balističko testiranje p-
aramidnih kompozita i impakt tester analiza Kolon kompozita. Mehanička svojstva svih kompozita
su bila testirana pomoću dinamičko mehaničke analize (DMA). Ključne reči: p-aramidni kompoziti, silika nanočestice, ugljenične nanocevi, AMEO silan, $\mathrm{PVB} / \mathrm{SiO}_{2}$ nanovlakna, balističko testiranje, impakt testiranje.

Originalni naučni rad

Primljeno za publikovanje: 01. 06. 2014.

Prihvaceno za publikovanje: 12. 08. 2014. 